\title{
A Near Ultraviolet Optically Pumped Vertical Cavity Laser
}

\author{
Hailong Zhou, M. Diagne, E. Makarona, and A.V. Nurmikko \\ Department of Physics and Division of Engineering \\ Brown University, Providence RI 02912, USA \\ J. Han, K. E. Waldrip, and J. J. Figiel \\ Sandia National Laboratories, Albuquerque, NM 87111, USA
}

\begin{abstract}
Optically pumped near ultraviolet vertical cavity laser operation (VCSEL) has been obtained under quasi-continuous wave conditions at room temperature near $383 \mathrm{~nm}$ from shallow InGaN/GaN multiple quantum wells (MQW). Low loss optical resonators were fabricated by using in-situ grown $(\mathrm{Al}, \mathrm{Ga}) \mathrm{N}$ distributed Bragg reflectors that featured strain engineering design for excellent optical morphology, in combination with low loss dielectric multilayer mirrors.
\end{abstract}




\section{DISCLAIMER}

This report was prepared as an account of work sponsored by an agency of the United States Government. Neither the United States Government nor any agency thereof, nor any of their employees, make any warranty, express or implied, or assumes any legal liability or responsibility for the accuracy, completeness, or usefulness of any information, apparatus, product, or process disclosed, or represents that its use would not infringe privately owned rights. Reference herein to any specific commercial product, process, or service by trade name, trademark, manufacturer, or otherwise does not necessarily constitute or imply its endorsement, recommendation, or favoring by the United States Government or any agency thereof. The views and opinions of authors expressed herein do not necessarily state or reflect those of the United States Government or any agency thereof. 


\section{DISCLAIMER}

\section{Portions of this document may be illegible in electronic image products. Images are produced from the best available original document.}


One current challenge for III-nitride based lasers is the extension to the near ultraviolet (NUV) regime below $400 \mathrm{~nm}$. Application areas, including chemical/biochemical sensing, would benefit from compact NUV coherent light sources. In parallel, there are early precursors for nitride lasers in vertical cavity, surface emitting geometry in the blue. Stimulated surface emission $[1,2]$, including VCSEL operation with well defined far field patterns [3], has been observed in optically pumped structures that feature specific fabrication paths to low-loss vertical microresonators.

In this paper, we utilize this experience to demonstrate quasi-continuous wave (cw) operation, at room temperature, of an optically pumped $\mathrm{In}_{\mathrm{x}} \mathrm{Ga}_{1-\mathrm{x}} \mathrm{N}(\mathrm{x} \sim 0.03) \mathrm{MQW}$ VCSEL at near $\lambda=383 \mathrm{~nm}$. We employ a vertical cavity scheme which combines a high reflectivity in-situ grown multilayer $\mathrm{GaN} / \mathrm{Al}_{0.25} \mathrm{Ga}_{0.75} \mathrm{~N}$ and post-growth dielectric $\mathrm{SiO}_{2} / \mathrm{HfO}_{2}$ distributed Bragg reflector (DBR). The in-situ grown nitride $\mathrm{DBR}$ is designed by inclusion of AlN strain compensating interlayers within the multilayer stack, which serve to eliminate tension-induced cracking [4] usually encountered during growth of $\mathrm{AlGaN} / \mathrm{GaN}$ heterostructures on $\mathrm{GaN}$. The presence of cracks, which propagate along well-defined crystallographic planes is a major impediment in a nitride VCSEL since they form 'accidental' resonators which greatly enhance the onset of lateral stimulated emission along the heterostructure layer plane, disabling true VCSEL operation [3]. The low index of refraction contrast between GaN and AIGaN (or AIN) demands a large number of layer pairs for high reflectivity. In this work, $\mathrm{R}=0.99$ has been reached, an adequate value compensated by the top dielectric DBRs $(R=0.995)$ in our 'hybrid' microresonators. Hybrid structures were used by Someya et al [1]. Many reports have 
appeared on the growth of $(\mathrm{Al}, \mathrm{GaN})$-based DBRs including recent advances by $\mathrm{Ng}$ et al [5] using MBE growth techniques for GaN/AIN broad bandwidth mirrors. We believe that the combination of high reflectivity and crack-free morphology in the as-grown DBRs achieved in this work has not been reached todate.

The III-nitride heterostructure was grown by organometallic vapor phase epitaxy (OMVPE) on (0001) sapphire substrate. Following the growth of $1 \mu \mathrm{m} \mathrm{GaN}$ using a standard 2-step nucleation [6], a $200 \AA$ thick AlN layer was grown for strain compensation of the subsequent 60 layer pairs of the quarter-wave $\mathrm{GaN} / \mathrm{Al}_{0.25} \mathrm{Ga}_{0.75} \mathrm{~N}$ stack. Subsequent insertion of additional AIN strain relief layers every 20 or so layer pairs greatly reduces the number of cracks in such a thick mirror structure $(\sim 5 \mu \mathrm{m})$ so that crack-free wafer surfaces were obtained over several $\mathrm{cm}^{2}$ [4]. A peak reflectivity of $\mathrm{R}=0.99$ was measured using a calibrated standard, and the spectral width of the maximum reflectance band was approximately $15 \mathrm{~nm}$. The active region was grown directly atop the $\mathrm{GaN} /(\mathrm{Al}, \mathrm{GaN}) \mathrm{DBR}$, composed of $20 \mathrm{In}_{0.03} \mathrm{Ga}_{0.97} \mathrm{~N}$ quantum wells $\left(\mathrm{L}_{\mathrm{w}}=40 \AA\right)$ with GaN barriers $\left(L_{B}=60 \AA\right)$. The as-grown $\mathrm{DBR}$ and the $\mathrm{QW}$ indium concentration were designed for spectral overlap between the high reflectivity region of the former with the photoluminescence emission of the latter. The structure was capped by a $1000 \AA$ thick $\mathrm{Al}_{0.1} \mathrm{Ga}_{0.9} \mathrm{~N}$ carrier confinement layer. Finally, a multilayer $\lambda / 4$ stack of $\mathrm{SiO}_{2} / \mathrm{HfO}_{2}$ was deposited by reactive ion beam sputtering. $\mathrm{HfO}_{2}$ is a high index, low absorption material in the NUV (to below $300 \mathrm{~nm}$ ), with high quality crystal microstructure [3]. The broad reflection bandwidth $(-80 \mathrm{~nm})$ of the dielectric DBR was tailored to overlap the near bandedge (In, Ga) N emission. The growth of the nitride heterostructure was optimized for 
high optical flatness as good morphology is crucial to the realization of true VCSEL operation. AFM studies of the surface of the as-grown wafer and the complete microcavity indicated a mean roughness of approximately $2 \mathrm{~nm}$ over areas on the order of several hundred $\mu \mathrm{m}^{2}$.

The vertical cavity structures were optically pumped by a frequency tripled, continuous-wave (cw) modelocked Nd:YAG laser at $355 \mathrm{~nm}$, operating at a repetition rate of $76 \mathrm{MHz}$. The individual pulse duration was approximately $0.1 \mathrm{nsec}$ and the radiation was focused at near normal incidence to $\mathrm{a} \approx 20 \mu \mathrm{m}$ diameter spot. The high repetition rate pumping is referred to as quasi-cw, as used in the literature. The wavelength of excitation laid outside the reflectance band of the top dielectric DBRs and slightly below the bandgap of the top AlGaN confinement layer, ensuring a creation of electron-hole pairs directly into the InGaN QWs. Given the thickness of the InGaN MQW (800 $\AA$ ), only a fraction of the pump photons (estimated less than 25\%) were usefully absorbed. Figure 1(a) shows the room temperature spontaneous emission spectrum at an average incident power of approximately $14 \mathrm{~mW}$. Two well defined cavity modes are seen, while a third lies at the rapidly falling edge of reflectivity band of the $\mathrm{GaN} /(\mathrm{Al}, \mathrm{Ga}) \mathrm{N}$ bottom $\mathrm{DBR}$, and is thus strongly broadened. Within the high-Q region the modal linewidth is approximately $0.8 \mathrm{~nm}$, limited by a combination of the reflectivity of the nitride DBR and scattering from residual morphological roughness presently under investigation. Figure 1(b) shows the emission spectrum from a device under photopumping at an incident average pump power of approximately $40 \mathrm{~mW}$, exceeding the lasing threshold. The spectral width of the emission at $383.2 \mathrm{~nm}(<0.1 \mathrm{~nm})$ was 
unresolved by our equipment. Above threshold, an intense low divergence beam of circular cross section was observed visually in the laboratory with fluorescent screens. A portion of the beam is shown in the photo as inset of Fig. 2, where a screen was placed along the beam of circular cross section, to scatter light into a blue enhanced digital camera. We measured an angular (full)width of 7.4 degrees, in very good agreement with the expected divergence dictated by the device aperture, as defined by the pump spot size.

Figure 2 shows input/output power characteristics of a particular device where the above referred spectral coincidences are nearly optimal. The lasing threshold occurs at a rather low average pump power of $30 \mathrm{~mW}$, while average output powers up to $3 \mathrm{~mW}$ were measured. However, finite thickness variation across the wafer led to spectral shifts of the cavity modes (relative to InGaN MQW gain spectrum) so that significant increases in threshold were encountered for devices fabricated from near the edge of the wafer (up to $100 \mathrm{~mW}$ beyond). It was possible to 'lose' the lasing altogether. When accounting for the optical excitation volume, the fractional absorption of the pump, and using an electron-hole recombination time of approximately $0.5 \mathrm{nsec}$, we estimate that the threshold in Fig. 2 corresponds roughly to a carrier density of approximately $10^{19} \mathrm{~cm}^{-3}$. Such a density is within the range of typical injection conditions employed in the best edge emitting blue and violet (In, Ga)N MQW diode lasers. It is encouraging, given the relatively shallow $\mathrm{QWs}\left(\Delta \mathrm{E}_{\mathrm{G}} \sim 160 \mathrm{meV}\right)$ employed in our structures (low indium concentration). Still, absolute efficiency of the VCSELs was difficult to establish at this point, given the uncertainty in the relevant parameters (fractional pump absorption and 
possible carrier overflow in the QWs), factors which also make the estimate of the threshold carrier density only a rough guide.

The research at Brown was supported by the U.S. National Science Foundation. Sandia is a multiprogram laboratory operated by Sandia Corporation, a Lockheed Martin Company, for the United States Department of Energy under Contract DE-AC0494AL85000. 


\section{References:}

[1] T. Someya, R. Werner, A. Forchel, M. Catalano, R. Cingolani, and Y. Arakawa, "Room Temperature Lasing at Blue Wavelengths in Gallium Nitride Microcavities", Science 285, 1905-1906 (1999)

[2] I. L. Krestnikov, W. V. Lundin, A. V. Sakharov, V. A. Semenov, A. S. Usikov, A. F. Tsatsul'nikov, Zh. I. Alferov, N. N. Ledentsov, A. Hoffmann, and D. Bimberg, "Roomtemperature photopumped InGaN/GaN/AlGaN vertical-cavity surface-emitting laser, Appl. Phys. Lett. 75, 1192-1194 (1999)

[3] Y.-K. Song, A. V. Nurmikko, and R.P. Schneider, C.P. Kuo, M.R. Krames, R.S. Kern, C. Carter-Coman, and F.A. Kish, "A Quasi-Continuous Wave, Optically Pumped Blue Vertical Cavity Surface Emitting Laser“, Appl. Phys. Lett. 76, 1662-1664 (2000)

[4] K. E. Waldrip, J. Han, J. J. Figiel, H. Zhou, M. Diagne, , and A. V. Nurmikko, "Stress Engineering during Metalorganic Chemical Vapor Deposition of AlGaN/GaN Distributed Bragg Reflectors", submitted to Appl. Phys. Lett.

[5] H. M. Ng, T. D. Moustakas, and S. N. G. Chu, "High reflectivity and broad bandwidth AIN/GaN distributed Bragg reflectors grown by molecular-beam epitaxy", Appl. Phys. Lett. 76, 2818-2820 (2000) 
[6] J. Han, T. -B. Ng, R. M. Biefeld, M. H. Crawford, and D. M. Follstaedt, "The effect of $\mathrm{H} 2$ on morphology evolution during GaN metalorganic chemical vapor deposition", Appl. Phys. Lett. 71, 3114-3116 (1997) 


\section{Figure Captions:}

Figure 1: (a) Spontaneous emission spectra at excitation level of $45 \%$ relative to threshold; (b) spectrum of VCSEL emission at $132 \%$ relative to threshold.

Figure 2: Average input vs. output power of a VCSEL device. The inset shows the beam far field (side) profile captured on a screen. 

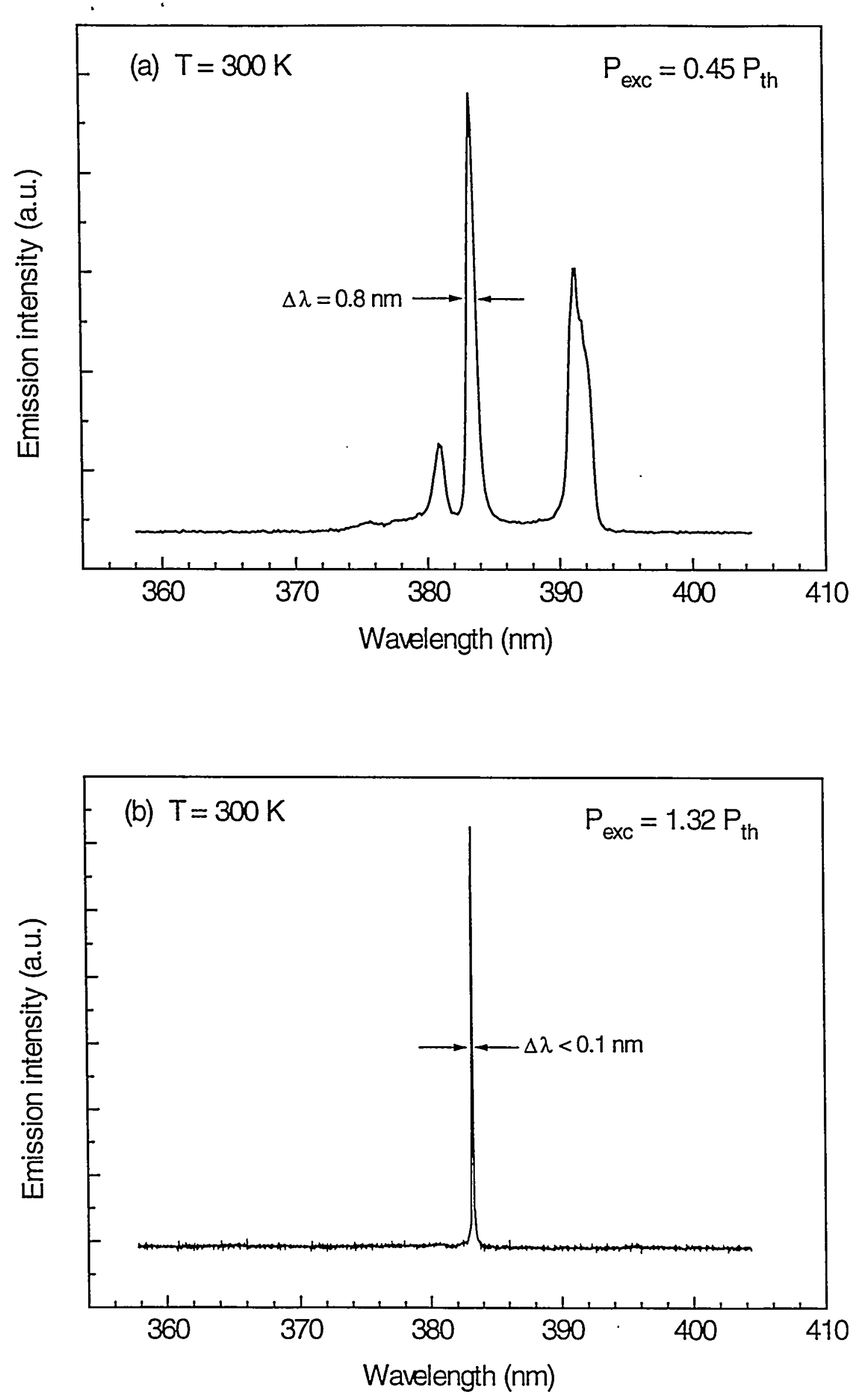


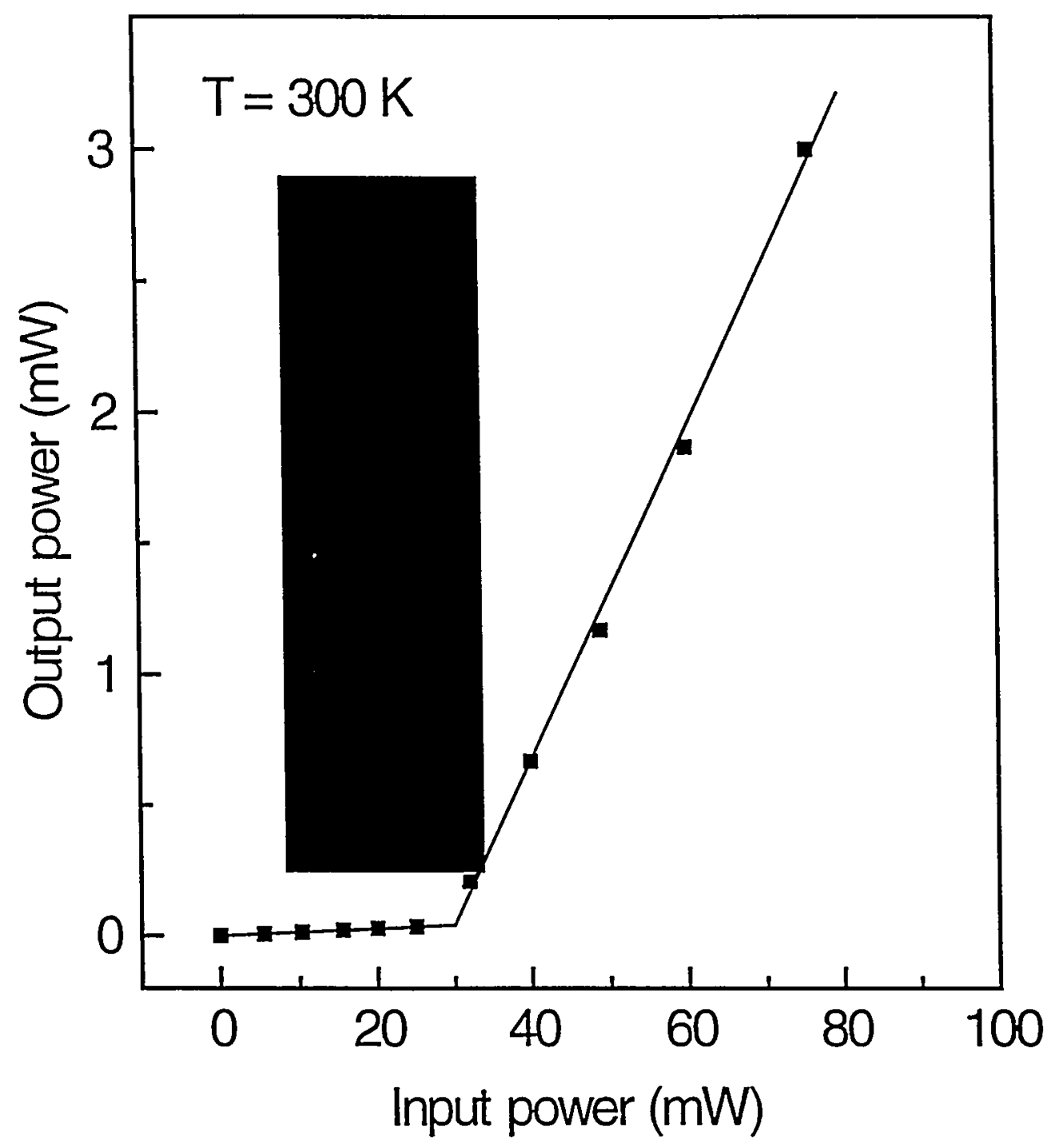

